\title{
Degree of conversion, translucency and intrinsic color stability of composites during surface modeling with lubricants
}

Ana Margarida dos Santos Melo', Thiago Jonathan Silva dos Santos ${ }^{1}$, Matheus Dantas Tertulino ${ }^{1}$, Maria Cristina dos Santos Medeiros ${ }^{2}$, Ademir Oliveira da Silva $^{3}$, Boniek Castillo Dutra Borges ${ }^{2}$

'DDS, Department of Dentistry, Federal University of Rio Grande do Norte (UFRN), Natal, Rio Grande do Norte, Brazil.

${ }^{2} \mathrm{PhD}$, Associate Professor Department of Dentistry, Federal University of Rio Grande do Norte (UFRN), Natal, Rio Grande do Norte, Brazil.

${ }^{3} \mathrm{PhD}$, Associate Professor, Institute of Chemistry, Federal University of Rio Grande do Norte (UFRN), Natal, Rio Grande do Norte, Brazil.
Corresponding author: Ana Margarida dos Santos Melo, 35 President Juscelino Kubitschek street, Natal-RN 59069-170, Brazil; Tel.: +55-84-98600-3561;

Fax + 55-84-3215-4101;

email: anamdsmelo@gmail.com

Received: February 27, 2018

Accepted: June 24, 2018
The tackiness presented by resins causes problems in performing the incremental technique, which can be improved by using lubricants in handling. Aim: To evaluate the influence of two adhesive systems as brush lubricants on the degree of conversion, translucency and intrinsic color stability of composite resins. Methods: Samples ( $n=10)$ were fabricated according to the composites (Filtek Z350 XT, IPS Empress Direct, and Esthet X HD), shades (bleach shade and A2), and lubricants used (Adper Single Bond 2, Adper Scotchbond Multi-Purpose bonding agent, and no lubricant). Single composite increments were inserted into a Teflon mold. The composite surface was then modeled using a brush dipped in an adhesive system. The control group was fabricated with no additional modeling. The surface degree of conversion (DC) was measured using Fourier transform infrared spectroscopy; translucency and intrinsic color stability were accessed using a spectrophotometer. Data were analyzed using three-way ANOVA and the Tukey test $(p<0.05)$. Results: Scotchbond Multi-Purpose decreased the DC of all composites and shades in comparison with the control group $(p<0.05)$, although it did not decrease color stability $(p<0.05)$. The bleach shade of IPS Empress Direct and Esthet X HD showed higher translucency than the A2 shade when lubricated with the adhesive systems $(p<0.05)$. Conclusion: Therefore, the two tested adhesive systems used as brush lubricants on composites promoted changes to the surface degree of conversion and aesthetic properties.

KEYWORDS: Composite resins. Dentin-bonding agents. Surface properties 


\section{Introduction}

The current emphasis in aesthetic dentistry has placed great importance on the achievement of a perfect smile. Due to the request for white teeth, individuals often require tooth bleaching with carbamide or hydrogen peroxides. The use of bleach shade composite resins is then of great relevance, since restorations that were completed prior to tooth bleaching should be replaced, as the peroxides do not change the composite color ${ }^{1}$. Therefore, obtaining adequate physical and aesthetic properties of bleach shade composite resins can prolong the lifetime of tooth restorations using bleach shade composite resins.

Bleach shade composites can present changes in chemical composition when compared with composites of traditional shades, especially regarding the photoinitiator system. Camphorquinone is unstable and tends to yellow over time due to its combination with tertiary amines ${ }^{2}$. Therefore, it has been replaced with less yellow photoinitiators, such as phenylpropanedione (PPD), trimethylbenzoyl-diphenyl-phosphine oxide (TPO), and phenylbis (2,4,6-trimethylbenzoyl)-phosphine oxide (BAPO) 3,4 to decrease yellowing over time. On the other hand, the organic matrix of bleach shade composites has not changed in comparison with those traditional shades. Stickiness between the composite and the dental instrument still remains due to the presence of viscous monomers ${ }^{5}$, causing difficulty in modeling the material ${ }^{6}$.

Instrument lubricants have been used to reduce stickiness between the composite and the instruments such as brushes to facilitate composite modeling and prevent drag ${ }^{7,8}$. However, the effects of these lubricants on the physical properties of the composites and the longevity of the restorations are not yet fully clarified, especially for bleach shade composites. Laboratory studies have indicated that the use of lubricants on instruments during composite insertion does not negatively affect the cohesive and flexural properties ${ }^{6-8}$. In relation to the surface properties, the impregnation of adhesives and alcohol can alter the degree of conversion and the crosslink density of some nanocomposites with traditional shades ${ }^{9}$. It is known that a low degree of conversion is associated with increased growth of biofilm, the release of monomers, composite solubility, and greater susceptibility to staining ${ }^{10}$.

When considering optical properties, translucency can be described as a state between complete transparency and complete opacity ${ }^{11}$, and is one of the factors responsible for influencing the final color of the composite ${ }^{12}$. These optical properties must be faithfully reproduced by the restorations for a natural comparison with natural teeth ${ }^{13}$

When taking into account the emerging relevance of restorative procedures after tooth bleaching using bleach shade composites, the present study aimed to evaluate the influence of different brush lubricants on the degree of conversion, translucency, and intrinsic color stability of composite resins of bleach and conventional A2 shades. The null hypothesis tested is that the lubricants do not affect the degree of conversion, the intrinsic color stability, or the translucency of the composite resins. 


\section{MATERIALS AND METHODS}

\section{Experimental design and preparation of samples}

This study implemented a $3 \times 2 \times 3$ factorial design. Three commercial brands of composites (Filtek Z350XT [XT], 3M ESPE, St Paul, MN, USA; IPS Empress Direct [ED], Ivoclar Vivadent, AG, Schaan, Liechtenstein; and Esthet X HD [HD], Dentsply Caulk, Milford, DE, USA), in two shades (bleach and A2) and three lubricants (Adper Single Bond 2 [SB], 3M ESPE, St Paul, MN, USA; or Adper Scotchbond Multi-Purpose Adhesive [MP], 3M ESPE, St Paul, MN, USA), or no lubricant were the factors under study. The degree of conversion, intrinsic color stability, 24-h translucency, and 30-day translucency were the response variables. The compositions of the materials used in this study are listed in Table 1.

Table 1. Lot and composition of the materials used in the study.

\begin{tabular}{|c|c|c|c|}
\hline Product & Manufacturer & Lot & Composition (\%wt) \\
\hline Filtek Z350 XT & $\begin{array}{l}\text { 3M ESPE, St. } \\
\text { Paul, MN, USA }\end{array}$ & 1520800607 & $\begin{array}{l}\text { UDMA (1-10\%), Bis-EMA (1-10\%), Bis-GMA }(1-10 \%), \text { TEGDMA } \\
(<5 \%) \text {, Polyethylene glycol dimethacrylate }(<5 \%), \text { Silane } \\
\text { treated zirconia (1-10\%), 2,6-di- Butyl-p-cresol (BHT) }(<0.5 \%), \\
\quad \text { Silane treated ceramics }(60-80 \%) \text {, nanofiller }(1-10 \%)\end{array}$ \\
\hline $\begin{array}{l}\text { IPS Empress } \\
\text { Direct }\end{array}$ & $\begin{array}{l}\text { Ivoclar } \\
\text { Vivadent AG, } \\
\text { Schaanm, } \\
\text { Liechtenstein }\end{array}$ & $\begin{array}{l}\text { S10171 } \\
\text { T28435 }\end{array}$ & $\begin{array}{c}\text { UDMA (10-25\%), Ytterbium trifluoride (3-10\%), } \\
\text { Tricyclodocane dimethanol dimethacrylate (3-10\%), } \\
\text { BisGMA }(2.5-3 \%)\end{array}$ \\
\hline Esthet X HD & $\begin{array}{l}\text { Dentsply } \\
\text { Caulk, Milford, } \\
\text { DE, USA }\end{array}$ & $\begin{array}{l}025210 G \\
005649 G\end{array}$ & $\begin{array}{c}\text { Glass fibers loose - special purpose }(<50 \%) \text {, Frits chemical } \\
(<30 \%) \text {, TEGDMA }(<20 \%) \text {, Urethane modified bis- GMA } \\
\text { dimethacrylate }(<10 \%) \text {, Silica amorphous - fumed }(<10 \%), \\
\text { Silica amorphous }(<10 \%)\end{array}$ \\
\hline $\begin{array}{l}\text { Adper Single } \\
\text { Bond } 2 \\
\text { Adhesive }\end{array}$ & $\begin{array}{l}\text { 3M ESPE, St. } \\
\text { Paul, MN, USA }\end{array}$ & N508311 & $\begin{array}{c}\text { Ethyl alcohol (25-35\%), BisGMA (10-20\%), UDMA } \\
(1-5 \%), \text { HEMA (5-15\%), Glycerol 1,3-dimethacrylate } \\
(5-10 \%) \text {, Nanofiller (20\%), Copolymer of acrylic acid } \\
\text { and itaconic (5-10\%), Water }(<5 \%) \text {, Diphenylodonium } \\
\text { hexafluorophosphate }(<1 \%), \text { EDMAB }(<1 \%)\end{array}$ \\
\hline $\begin{array}{l}\text { Adper } \\
\text { Scotchbond } \\
\text { Multi-Purpose } \\
\text { Adhesive }\end{array}$ & $\begin{array}{l}\text { 3M ESPE, St. } \\
\text { Paul, MN, USA }\end{array}$ & N571827 & $\begin{array}{l}\text { BisGMA (60-70\%), HEMA (30-40\%), triphenyl antimony } \\
\qquad(<1 \%)\end{array}$ \\
\hline \multicolumn{4}{|c|}{$\begin{array}{l}\text { Legend: } \\
\text { UDMA: Diurethane dimethacrylate } \\
\text { BisEMA: Bisphenol A polyethylene glycol diether dimethacrylate } \\
\text { BisGMA: Bisphenol A diglycidyl ether dimethacrylate } \\
\text { TEGDMA: Triethylene glycol dimethacrylates } \\
\text { HEMA: 2-hydroxyethyl methacrylate } \\
\text { Nanofiller: Silane treated silica } \\
\text { EDMAB: Ethyl 4-dimethylaminobenzoate }\end{array}$} \\
\hline
\end{tabular}

A total of 180 specimens were prepared according to different groups ( $n=10$ per group) (Figure 1). Composites were inserted into Teflon molds (5 mm diameter $\times 2$ $\mathrm{mm}$ height) with a spatula (Thompson no. 1, Thompson Dental Products, Houston, TX, USA) in a single increment. The composite surface was then modeled using a flat composite brush (n 1021, Hot Spot Design, Cugy, Switzerland) coated with an 


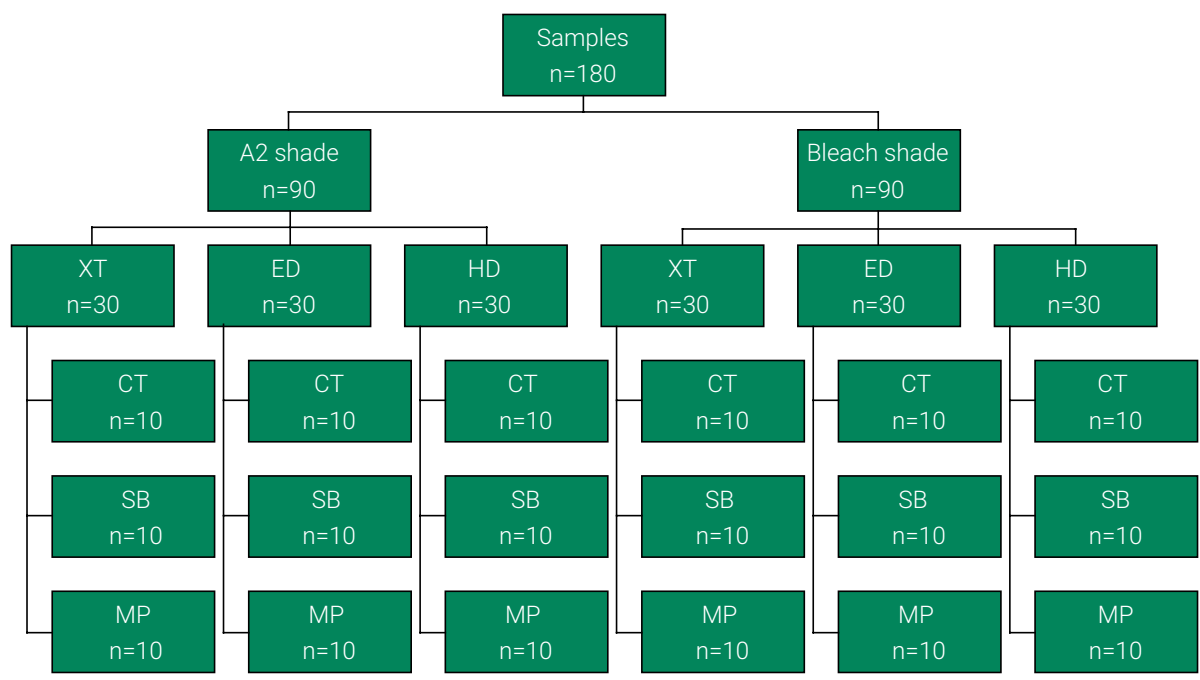

Legend:

A2: Composites in color A2

Bleached teeth: Composites for bleached teeth

XT: Filtek Z350 XT

ED: IPS Empress Direct

HD: Esthet X HD

CT: Control Group

SB: Adper Single Bond 2 Adhesive

MP: Adper Scotchbond Multi-Purpose Adhesive ( $n^{\circ} 3$ )

Figure 1. Distribution of the samples according to the type and shade of composite resins and lubricant used.

adhesive system SB and MP. No material was impregnated in the brush for the control group (CT). One drop of the material was applied to the brush head to coat the brush with adhesive systems, and excess was removed by stroking onto a glass plate for $3 \mathrm{~s}$ on each side of the brush. Sculpting consisted of three sweeping motions of the adhesive-dampened instrument against each half of the circular composite surface (a total of six motions for each sample) ${ }^{9}$.

The composite was photoactivated for 20 seconds using a light emitting diode (LED) (Coltolux LED; Coltène Whaledent, Altstätten, Switzerland) with a light intensity of $1200 \mathrm{~mW} / \mathrm{cm}^{2}$. A microscopy slide was pressed on the top of the samples to obtain a smooth surface, thus standardizing the distance between the light source and the composite resin during photoactivation. The tip of the light emitting diode was placed in contact and perpendicular to the slide's surface, covering the entire surface of the sample, since the tip diameter was larger than the sample diameter. After photoactivation, the specimens were removed and the excess material was removed with a scalpel blade. The specimens were stored in dry, light-proof containers in an oven at $37^{\circ} \mathrm{C}$ for 24 hours.

\section{Degree of Conversion (DC)}

The DC was evaluated 24 hours after curing using a Fourier Transform Infrared spectrometer (FTIR) (Spectrum100 FTIR/ATR; Perkin Elmer, Shelton, CT, USA) coupled to an atten- 
uated total reflectance device. Absorption spectra of the unpolymerized and the polymerized composite resins were obtained from the region between 4000 and $650 \mathrm{~cm}^{-1}$, with 32 scans at $4 \mathrm{~cm}^{-1}$. The $1590-1660 \mathrm{~cm}^{-1}$ interval was chosen to observe the absorbance at 1608 and $1638 \mathrm{~cm}^{-1}$, indicating the absorption peaks of the bisphenol aromatic vinyl bonds and the aliphatic bonds of the methacrylate functional group, respectively. The DC (\%) was calculated using the following equation: $\mathrm{DC}(\%)=100 \times\left(1-\left[R_{\text {polymerized }} / R_{\text {unpolymerized }}\right]\right)$ where $R$ is the ratio between the absorbance peak at $1638 \mathrm{~cm}^{-1}$ and $1608 \mathrm{~cm}^{-114}$. Samples were then stored in water at $37^{\circ} \mathrm{C}$ for 24 hours.

\section{Intrinsic Color Stability $(\Delta \mathrm{E})$ and Translucency}

The intrinsic color stability and translucency evaluations were performed using a spectrophotometer (VITA Easyshade, Vita Zahnfabrik, Bad Sackingen, Germany). Following $24 \mathrm{~h}$ and 30 days of water storage, the initial (Ti) and final (Tf) color values, respectively, were taken using standard white and black ceramic backgrounds. Each specimen and surface was assessed five times at the same assessment time and the average value was calculated. A silicon (Express XT, 3M ESPE, St. Paul, MN, USA) barrier was fabricated to surround the interface between the specimen and the spectrophotometer tip to avoid interference from external light. The silicon barrier allowed the tip to be placed on the same area of the specimen for both color measurements.

The color was measured according to the CIEL*a*b* color scale, as recommended by the International Commission on Illumination. Spectrophotometers collect spectral data from the reflected light and automatically translate these data into the three-color coordinates ( $L^{*}=$ lightness, $+a^{*}=$ red, $-a^{*}=$ green, $+b^{*}=$ yellow, $-b^{*}=$ blue). The intrinsic color stability $(\Delta \mathrm{E})$ was calculated between $\mathrm{Tf}$ and $\mathrm{Ti}$ for readings made on the white background using the following equation: $\Delta E=\left[\left(\Delta L^{*}\right)^{2}+\left(\Delta a^{*}\right)^{2}+\left(\Delta b^{*}\right)^{2}\right]^{1 / 2}$, in which $\Delta L^{*}$ represents $L^{*}$ final - $L^{\star}$ initial; $\Delta a^{\star}$ represents $a^{*}$ final - $a^{\star}$ initial; e $\Delta b^{*}$ represents $b^{\star}$ final $-b^{\star}$ initial ${ }^{15}$.

The 24-h and 30-day translucencies were calculated using the translucency formula $(T)$ for each period using the following equation: $T=\left(L_{w}{ }^{*}-L_{B}{ }^{*}\right)^{2}+\left(a_{w}{ }^{*}-a_{B}{ }^{*}\right)^{2}+\left(b_{w}{ }^{*}-b_{B}{ }^{*}\right)^{1 / 2}$, where the subscripts ' $W$ ' and ' $B$ ' refer to the CIEL*a* $b^{\star}$ values for each specimen on white background and black background, respectively ${ }^{16}$.

\section{Statistical analysis}

The data of the DC, intrinsic color stability, 24-h and 30-day translucencies were analyzed statistically by three-way ANOVA and Tukey's post-test with a significance level of $5 \%(p<0.05)$. All analyses were performed using ASSISTAT 7.7 beta software.

\section{RESULTS}

DC

There was a statistically significant difference between composites $(p<0.05)$, between lubricants $(p<0.05)$ and the interaction between composites and lubricants $(p<0.05)$. The comparisons between the groups are listed in Table 2. When com- 
Table 2. Means (standard deviations) of the degree of conversion (\%) according to the shade, composite and lubricant used.

\begin{tabular}{lcccc}
\hline \multirow{2}{*}{ Shade } & Composite & \multicolumn{3}{c}{ Lubricant } \\
\cline { 2 - 5 } & & None & Single Bond 2 & Scotchbond \\
\hline \multirow{3}{*}{ A2 } & Z350 XT & $73.8(4.7) \mathrm{Aa}^{*}$ & $71.1(6.2) \mathrm{Ab}^{*}$ & $51.2(7.4) \mathrm{Ba}^{*}$ \\
\cline { 2 - 5 } & Empress Direct & $71.3(12.2) \mathrm{Aa}$ & $58.2(5.0) \mathrm{Bc}$ & $41.4(8.3) \mathrm{Bb}$ \\
\cline { 2 - 5 } & Esthet X HD & $78.3(8.6) \mathrm{Ba}$ & $88.6(4.1) \mathrm{Aa}$ & $57.5(7.0) \mathrm{Ca}^{*}$ \\
\hline \multirow{3}{*}{$\begin{array}{l}\text { Bleached } \\
\text { teeth }\end{array}$} & Z350 XT & $84.1(7.5) \mathrm{Aa}$ & $79.4(4.5) \mathrm{Aa}$ & $63.1(10.7) \mathrm{Ba}$ \\
\cline { 2 - 4 } & Empress Direct & $77.6(8.2) \mathrm{Aa}$ & $64.3(7.6) \mathrm{Bb}$ & $41.5(6.1) \mathrm{Cb}$ \\
\cline { 2 - 4 } & Esthet X HD & $78.4(8.5) \mathrm{Aa}$ & $83.8(5.2) \mathrm{Aa}$ & $66.5(8.4) \mathrm{Ba}$ \\
\hline
\end{tabular}

Means followed by distinct upper case letters denote statistically significant differences between lubricants for the same shade and composite $(p<0.05)$. Means followed by lower case letters denote statistically significant differences between composites for the same shade and lubricant $(p<0.05)$. Means followed by an asterisk (*) denote statistically significant differences between shades for the same composite and lubricant $(p<0.05)$.

pared to the control group, MP reduced the DC of all composites. SB decreased the DC for both ED composite shades, and only increased the DC of the HD composite in A2 shade. There was no statistically significant difference in the control groups for either shade. There was a statistically significant difference between the shades for the XT composite when interacting with all the lubricants, and only for the HD when lubricated with MP.

\section{Intrinsic Color Stability}

There was a statistically significant difference between composites $(p<0.05)$, between lubricants $(p<0.05)$ and in the interaction between composites and lubricants $(p<0.05)$. The comparisons between the groups are listed in Table 3. MP promoted higher color change values for the HD composite in the A2 shade when compared to the control group. There was a statistically significant difference between the shades for the ED and HD composites in the control group, with higher color change values for the A2 shade.

Table 3. Means (standard deviations) of the intrinsic color stability $(\Delta \mathrm{E})$ according to the colors, resins and lubricants used.

\begin{tabular}{lcccc}
\hline \multirow{2}{*}{ Color } & Composite & \multicolumn{3}{c}{ Lubricant } \\
\cline { 2 - 5 } & & None & Single Bond 2 & Scotchbond \\
\hline \multirow{3}{*}{ A2 } & X350 XT & $3.0(1.0) \mathrm{Aa}$ & $3.0(0.9) \mathrm{Aa}$ & $2.3(1.1) \mathrm{Ab}$ \\
\cline { 2 - 5 } & Empress Direct & $4.0(1.6) \mathrm{Aa}$ & $2.0(0.8) \mathrm{Ab}$ & $2.8(0.9) \mathrm{Ab}$ \\
\cline { 2 - 5 } & Esthet X HD & $2.6(1.1) \mathrm{Ba}$ & $2.4(0.9) \mathrm{Bab}$ & $4.6(1.8) \mathrm{Aa}$ \\
\hline \multirow{3}{*}{$\begin{array}{l}\text { Bleached } \\
\text { teeth }\end{array}$} & X350 XT & $2.0(0.6) \mathrm{ABa}$ & $3.0(1.5) \mathrm{Aa}$ & $3.4(1.8) \mathrm{Bb}$ \\
\cline { 2 - 4 } & Empress Direct & $2.8(1.4) \mathrm{Aa}$ & $2.8(1.7) \mathrm{Aa}$ & $4.0(2.0) \mathrm{Aab}$ \\
\cline { 2 - 4 } & Esthet X HD & $1.4(0.8) \mathrm{Aa}$ & $2.6(1.2) \mathrm{Aa}$ & $4.3(1.6) \mathrm{Aa}$ \\
\hline
\end{tabular}

Means followed by distinct upper case letters denote statistically significant differences between lubricants for the same shade and composite $(p<0.05)$. Means followed by lower case letters denote statistically significant differences between composites for the same shade and lubricant $(p<0.05)$. Means followed by an asterisk (*) denote statistically significant differences between shades for the same composite and lubricant $(p<0.05)$. 


\section{4-h Translucency}

There was a statistically significant difference between composites $(p<0.05)$, between lubricants $(p<0.05)$ and in the interaction between composites and lubricants $(p<0.05)$. The comparisons among the groups are listed in Table 4. With the exception of composites for bleached teeth lubricated with MP, there was a statistically significant difference in translucency for all composites, including the control groups. Only the HD composite in the A2 shade showed no statistically significant difference between the lubricants used. There was an increase in the translucency with the use of lubricants for the XT and a decrease for the ED in both shades, whereas there was only a decrease in the HD composite. There was also a difference between the shades for all SB-lubricated composites and only for the MP-lubricated HD composite, as well as the control group for XT and HD composites.

Table 4. Means (standard deviations) of the translucency parameter after 24 hours of immersion in distilled water according to the colors, resins and lubricants used.

\begin{tabular}{lcccc}
\hline \multirow{2}{*}{ Color } & \multirow{2}{*}{ Composite } & \multicolumn{3}{c}{ Lubricant } \\
\cline { 2 - 5 } & & None & Single Bond 2 & Scotchbond \\
\hline \multirow{3}{*}{ A2 } & Filtek Z350XT & $5.5(1.0) \mathrm{Cb}^{*}$ & $7.0(0.8) \mathrm{Aa}^{\star}$ & $6.3(0.7) \mathrm{Ba}$ \\
\cline { 2 - 5 } & Empress Direct & $7.8(0.9) \mathrm{Aa}$ & $6.1(0.6) \mathrm{Cb}^{*}$ & $7.2(0.8) \mathrm{Ba}$ \\
\cline { 2 - 5 } & Esthet X HD & $4.6(1.0) \mathrm{Ac}$ & $4.6(0.6) \mathrm{Ac}^{\star}$ & $4.3(0.5) \mathrm{Ab}^{*}$ \\
\hline \multirow{2}{*}{$\begin{array}{l}\text { Bleached } \\
\text { teeth }\end{array}$} & Filtek Z350XT & $6.2(0.3) \mathrm{Cc}$ & $8.1(0.9) \mathrm{Aa}$ & $6.9(0.8) \mathrm{Ba}$ \\
\cline { 2 - 5 } & Empress Direct & $8.4(0.9) \mathrm{Aa}$ & $7.4(0.5) \mathrm{Bb}$ & $7.4(0.4) \mathrm{Ba}$ \\
\cline { 2 - 5 } & Esthet X HD & $7.3(0.9) \mathrm{Ab}$ & $6.2(0.3) \mathrm{Bc}$ & $6.7(0.9) \mathrm{Ba}$ \\
\hline
\end{tabular}

Means followed by distinct upper case letters denote statistically significant differences between lubricants for the same shade and composite $(p<0.05)$. Means followed by lower case letters denote statistically significant differences between composites for the same shade and lubricant $(p<0.05)$. Means followed by an asterisk $\left(^{*}\right)$ denote statistically significant differences between shades for the same composite and lubricant $(p<0.05)$.

\section{0-day Translucency}

There was a statistically significant difference between composites ( $p<0.05)$, between lubricants $(p<0.05)$ and in the interaction between composites and lubricants $(p<0.05)$. Comparisons between the groups are listed in Table 5. Only the XT composite in the A2 shade showed an increase in translucency when lubricated with SB and MP,

Table 5. Means (standard deviations) of the translucency parameter after 30 days of immersion in distilled water according to the colors, resins and lubricants used.

\begin{tabular}{lcccc}
\hline \multirow{2}{*}{ Color } & \multirow{2}{*}{ Composite } & \multicolumn{3}{c}{ Lubricant } \\
\cline { 2 - 5 } & & None & Single Bond 2 & Scotchbond \\
\hline \multirow{3}{*}{ A2 } & X350 XT & $5.2(1.0) \mathrm{Bb}^{\star}$ & $7.7(1.0) \mathrm{Aa}$ & $7.2(0.9) \mathrm{Aa}^{*}$ \\
\cline { 2 - 5 } & Empress Direct & $6.8(0.6) \mathrm{Aa}^{*}$ & $6.3(0.5) \mathrm{Ab}^{\star}$ & $6.5(0.6) \mathrm{Aa}^{*}$ \\
\cline { 2 - 5 } Bleach & Esthet X HD & $5.3(1.0) \mathrm{Ab}^{\star}$ & $4.5(0.6) \mathrm{Ac}^{\star}$ & $4.5(1.0) \mathrm{Ab}^{*}$ \\
\cline { 2 - 5 } & X350 XT & $6.9(0.7) \mathrm{Aa}$ & $7.7(0.9) \mathrm{Aa}$ & $7.1(0.7) \mathrm{Aa}$ \\
\cline { 2 - 5 } & Empress Direct & $7.9(0.9) \mathrm{Aa}$ & $7.9(0.9) \mathrm{Aa}$ & $7.4(0.9) \mathrm{Aa}$ \\
\hline
\end{tabular}

Means followed by distinct upper case letters denote statistically significant differences between lubricants for the same shade and composite $(p<0.05)$. Means followed by lower case letters denote statistically significant differences between composites for the same shade and lubricant $(p<0.05)$. Means followed by an asterisk (*) denote statistically significant differences between shades for the same composite and lubricant $(p<0.05)$. 
whereas only the HD composite in the bleach shade decreased its translucency when lubricated with SB. The comparison between the shades showed higher translucency values for all the composites in the control groups, while only the XT showed no difference for the other lubricants.

\section{DISCUSSION}

The null hypothesis tested in this study was rejected, since the use of lubricants promoted changes in the DC and optical properties of the tested composites in their different shades.

$\mathrm{DC}$ is the percentage of monomers that were converted into polymer during polymerization $^{17}$. As a consequence, its deficit implies weakening of the mechanical properties of the material, thereby affecting the quality of the formed resinous polymer ${ }^{18,19}$ and the restoration's longevity ${ }^{4}$. In fact, DC depends on the material components such as the type and concentration of monomers, photoinitiators, pigments, and filler content ${ }^{14,20,21}$. Light intensity of the photoactivation device, photoactivation time, and distance between the light source and composite also influence the final DC of the composite ${ }^{20}$.

In this study, MP decreased the DC for all the composites, regardless of the tested shades. MP is a bonding agent that does not contain solvent and has 60 to $70 \%$ of Bisphenol A glycidyl dimethacrylate (Bis-GMA), a high molecular weight monomer that promotes decreased DC in composite resins ${ }^{19} \mathrm{~A}$ higher incorporation of BisGMA at the composite surfaces that were lubricated with MP likely decreased the DC in comparison with the control group. In contrast, it is likely that more hydrophilic low molecular weight monomers remained in the brush after the solvent evaporation of SB due to its chemical composition. As low molecular weight monomers increase the DC of polymer-based materials ${ }^{19}$, it can presume that a positive interaction between the low molecular weight monomers of SB, the low molecular weight monomers and the pigments of the A2 shade HD occurred, which increased the DC of HD only for the A2 shade. On the other hand, the absence of TEGDMA in ED may have impaired a chemically positive interaction between the residual hydrophilic monomers that remained from SB on the brush with those of the composite, leading to decreased DC for ED. However, further chemical analysis should be performed to confirm these assumptions.

The fact that the bleach shade of XT presented a higher DC when compared to A2 for all the tested lubricants can probably be attributed to the difference in the nature and color of the pigments. Lighter pigments may be present in the bleach shade of $\mathrm{XT}$ than in the bleach shade of ED and HD, favoring greater absorption of light by photoinitiators and higher $\mathrm{DC}$ for $\mathrm{XT}{ }^{22}$.

Decreased DC is directly related to an intrinsic color change of composite resins due to the release of some coloring substances that can induce material discoloration ${ }^{23}$. However, in this study, composites lubricated with MP showed decreased DC, while only HD in the A2 shade presented a greater intrinsic color change. In fact, because DC was measured on the surface of the samples, it is likely that the color change of the entire sample was not only dependent on the color alteration caused on the surface of the samples. 
Tooth restoration color is directly influenced by the translucency and opacity of the composites ${ }^{1}$, which should be reproduced to better mimic the optical properties of dental tissues ${ }^{13}$. Composite translucency is most influenced by the organic matrix ${ }^{24}$ and the filler load content ${ }^{25}$. While the former is related to the absorption and reflection of light, the latter is responsible for the dispersion effect that may occur within the restoration structure ${ }^{26}$. Therefore, the way that light is absorbed, reflected, and scattered influences the composite translucency ${ }^{27}$. The increased translucency after 24 hours observed for XT when lubricated by MP and SB is probably due to the absence of oxidation products on the composite due to a greater synergetic interaction between the monomers from the same manufacturer. On the other hand, it is likely the interaction between the monomers from MP and SB with those from ED and HD might have generated oxidation products, which can increase the opacity of the composites ${ }^{27}$. However, further chemical analysis should be performed to confirm this assumption.

Studies have shown that storage in water or solutions with pigments can alter the translucency of composites, mainly due to the degradation of the resinous monomers and leaching of the charged particles ${ }^{28}$. Because translucency involves the amount of light transmitted through a material or body ${ }^{11}$, a less translucent material has fewer color pigments which can obstruct light penetration ${ }^{29}$. Thus, it is reasonable to assume that both lubricants might have promoted an increase in monomer leaching to ED and $\mathrm{HD}$ after 30 days of water storage, thereby increasing the translucency.

Some studies have shown that the use of adhesives between composite layers during the incremental technique does not negatively interfere with physical properties such as flexural and cohesive resistance ${ }^{7.8}$ or even that they can increase the physical stability of some composite resins ${ }^{30}$. However, the results of the present study did find a positive influence of the adhesive system used as brush lubricants on the surface and aesthetic properties of composite resins, since the application of a bonding agent as a brush lubricant induced reduced polymerization on the surface and color alterations. In fact, adhesive systems can not randomly be used as a brush lubricant for just any composite resin, so clinicians should be aware of this point. Further studies should be performed to analyze the influence of conventional brush lubricants on the surface properties of conventional and bleach shade composite resins.

The unavailability of details about the chemical composition of the products by the manufacturers was a limitation in this study, because knowing what kind of photoinitiators and pigments are present in the composites would help to understand the behavior of the composite resins and its interaction with the adhesive systems used in the performed analyses.

In conclusion, the two tested adhesive systems used as brush lubricants on composite surfaces in a bleach shade promoted changes to the degree of conversion, intrinsic color stability, 24-h translucency and 30-day translucency of all composites tested.

\section{Disclosure}

The authors do not have any financial interest in the companies whose materials are included in this article. 


\section{References}

1. Irawan BA, Irawan SN, Masudi SM, Sukminingrum N, Alam MK. 3D Surface Profile and Color Stability of Tooth Colored Filling Materials after Bleaching. Biomed Res Int. 2015;2015:327289. doi: 10.1155/2015/327289

2. Krämer N, Reinelt C, Richter G, Petschelt A, Frankenberger R. Nanohybrid vs fine hybrid composite in Class II cavities: clinical results and margin analysis after four years. Dent Mater. 2009 Jun;25(6):750-9. doi: 10.1016/j.dental.2008.12.003

3. Jiménez-Planas A, Martín J, Abalos C, Llamas R. Developments in polymerization lamps. Quintessence Int. 2008 Feb;39(2):e74-84.

4. Shin DH, Rawls HR. Degree of conversion and color stability of the light curing resin with new photoinitiator systems. Dent Mater. 2009 Aug;25(8):1030-8. doi: 10.1016/j.dental.2009.03.004.

5. Ogliari FA, Ely C, Zanchi CH, Fortes CB, Samuel SM, Demarco FF, et al. Influence of chain extender length of aromatic dimethacrylates on polymer network development. Dent Mater. 2008 Feb;24(2):165-71

6. Dunn WJ, Strong TC. Effect of alcohol and unfilled resin in the incremental buildup of resin composite. Quintessence Int. 2007 Jan;38(1):e20-6

7. Barcellos DC, Pucci CR, Torres CR, Goto EH, Inocencio AC. Effects of resinous monomers used in restorative dental modeling on the cohesive strength of composite resin. J Adhes Dent. 2008 Oct;10(5):351-4.

8. Perdigão J, Gomes G. Effect of instrument lubricant on the cohesive strength of a hybrid resin composite. Quintessence Int. 2006 Sep;37(8):621-5

9. de Paula FC, Valentin Rde S, Borges BC, Medeiros MC, de Oliveira RF, da Silva AO. Effect of instrument lubricants on the surface degree of conversion and crosslinking density of nanocomposites. J Esthet Restor Dent. 2016 Mar-Apr;28(2):85-91. doi: 10.1111/jerd.12182

10. Khalichi P, Singh J, Cvitkovitch DG, Santerre JP. The influence of triethylene glycol derived from dental composite resins on the regulation of Streptococcus mutans gene expression. Biomaterials. 2009 Feb;30(4):452-9. doi: 10.1016/j.biomaterials.2008.09.053.

11. Villarroel M, Fahl N, De Sousa AM, De Oliveira OB Jr. Direct esthetic restorations based on translucency and opacity of composite resins. J Esthet Restor Dent. 2011 Apr;23(2):73-87. doi: 10.1111/j.1708-8240.2010.00392.x

12. Johnston WM. Color measurement in dentistry. J Dent. 2009;37 Suppl 1:e2-6. doi: 10.1016/j. jdent.2009.03.011.

13. Lee YK, Lim BS, Kim CW. Difference in the colour and colour change of dental resin composites by the background. J J Oral Rehabil. 2005 Mar;32(3):227-33.

14. da Silva EM, Poskus LT, Guimarães JG. Influence of light-polymerization modes on the degree of conversion and mechanical properties of resin composites: a comparative analysis between a hybrid and a nanofilled composite. Oper Dent. 2008 May-Jun;33(3):287-93. doi: 10.2341/07-81.

15. International Commission on Illumination. Recommendations on uniform color spaces, color difference equations, psychometric color terms. Paris: Bureau Central de la CIE; 1978.

16. Johnston WM, Ma T, Kienle BH. Translucency parameter of colorants for maxillofacial prostheses. Int J Prosthodont. 1995 Jan-Feb;8(1):79-86.

17. Peutzfeldt A. Resin composites in dentistry: the monomer systems. Eur J Oral Sci. 1997 Apr;105(2):97-116.

18. Cadenaro M, Breschi L, Antoniolli F, Navarra CO, Mazzoni A, Tay FR, et al. Degree of conversion of resin blends in relation to ethanol content and hydrophilicity. Dent Mater. 2008 Sep;24(9):1194-200. doi: 10.1016/j.dental.2008.01.012. 
19. Gajewski VE, Pfeifer CS, Fróes-Salgado NR, Boaro LC, Braga RR. Monomers used in resin composites: degree of conversion, mechanical properties and water sorption/solubility. Braz Dent J. 2012;23(5):508-14

20. Moraes LG, Rocha RS, Menegazzo LM, de Araújo EB, Yukimito K, Moraes JC. Infrared spectroscopy: a tool for determination of the degree of conversion in dental composites. J Appl Oral Sci. 2008 MarApr;16(2):145-9.

21. Amirouche-Korichi A, Mouzali M, Watts DC. Effects of monomer ratios and highly radiopaque fillers on degree of conversion and shrinkage-strain of dental resin composites. Dent Mater. 2009 Nov;25(11):1411-8. doi: 10.1016/j.dental.2009.06.009.

22. Aguiar FH, Lazzari CR, Lima DA, Ambrosano GM, Lovadino JR. Effect of light curing tip distance and resin shade on microhardness of a hybrid resin composite. Braz Oral Res. 2005 Oct-Dec;19(4):302-6.

23. Janda R, Roulet JF, Kaminsky M, Steffin G, Latta M. Color stability of resin matrix restorative materials as a function of the method of light activation. Eur J Oral Sci. 2004 Jun;112(3):280-5.

24. Azzopardi N, Moharamzadeh K, Wood DJ, Martin N, van Noort R. Effect of resin matrix composition on the translucency of experimental dental composite resins. Dent Mater. 2009 Dec;25(12):1564-8. doi: 10.1016/j.dental.2009.07.011.

25. Lee YK. Influence of filler on the difference between the transmitted and reflected colors of experimental resin composites. Dent Mater. 2008 Sep;24(9):1243-7. doi: 10.1016/j.dental.2008.01.014.

26. Kim DH, Park SH. Evaluation of resin composite translucency by two different methods. Oper Dent. 2013 May-Jun;38(3):E1-15. doi: 10.2341/12-085-L.

27. Münchow EA, Sedrez-Porto JA, Piva E, Pereira-Cenci T, Cenci MS. Use of dental adhesives as modeler liquid of resin composites. Dent Mater. 2016 Apr;32(4):570-7. doi: 10.1016/j.dental.2016.01.002.

28. Ozakar Ilday N, Celik N, Bayindir YZ, Seven N. Effect of water storage on the translucency of siloranebased and dimethacrylate-based composite resins with fibres. J Dent. 2014 Jun;42(6):746-52. doi: 10.1016/j.jdent.2014.02.002.

29. Dietschi D. Free-hand bonding in the esthetic treatment of anterior teeth: creating the illusion. $J$ Esthet Dent. 1997;9(4):156-64. doi: doi.org/10.1111/j.1708-8240.1997.tb00936.x

30. Sideridou ID, Karabela MM, Bikiaris DN. Aging studies of light cured dimethacrylate-based dental resins and a resin composite in water or ethanol/water. Dent Mater. 2007 Sep;23(9):1142-9. 